\title{
Compensation for Harm Caused by Nuclear Installations: What's the Damage?
}

\begin{tabular}{|r|l|}
\hline Journal: & Journal of Property, Planning and Environmental Law \\
\hline Manuscript ID & JPPEL-06-2017-0020.R2 \\
\hline Manuscript Type: & Article \\
\hline Keywords: & nuclear, liability, compensation, impairment, environment, damage \\
\hline \multicolumn{2}{|c}{} \\
\end{tabular}




\title{
Compensation for harm caused by nuclear installations: What's the damage?
}

\author{
Robert G Lee and Radek Stech \\ Birmingham Law School and Exeter Law School \\ Introduction
}

It is hard to conceive of an environmental disaster with greater capacity for harm than a nuclear accident. The (still projected) costs related to the Fukushima nuclear disaster may run to 21.5 trillion yen ( $\$ 188$ billion), of which over one third (7.9 trillion yen) is accounted for by reparation and compensation with a further quarter (5.6 trillion yen) for the cost of treatment and storage of contaminated soil (Yasunari 2011; Obayashi and Hamada 2016). These costs in Japan, lying outside of any compensation regime, fall largely upon Tokyo Electric Power (TEPCO) and other utilities and are borne by cost cutting (and a return to hydrocarbon based energy) and higher utility bills. In Western Europe, international conventions provide for an international liability regime $^{1}$ for the payment of compensation following a nuclear incident (TouitouDurand, 2010). Recent changes to and in particular raised liability thresholds in these international conventions have generated revised compensation structures for nuclear accidents in the UK.

The Nuclear Installations (Liability for Damages) Order $2016^{2}$ ('2016 Order') amends the Nuclear Installations Act 1965 ('1965 Act') in order to comply with amended protocols ${ }^{3}$ to the Paris ${ }^{4}$ and Brussels Supplementary ${ }^{5}$ Conventions (McRae, 1998). The 1965 Act implements a strict liability regime on operators of nuclear licensed sites for injury or damage caused by a nuclear occurrence. Operators are required to put in place insurance or other provision to cover this liability. The changes made to this regime by the Order are wide ranging. For example, disposal sites for nuclear waste are brought within the regime. More potential claimants, including those suffering damage in a non-convention state with no nuclear installations, can claim up to the Convention limits. These liability caps will rise in a banded fashion, explained below, depending on the category of installation, in a move which broadly passes responsibility for nuclear damage away from government and more firmly onto the nuclear industry. Such a transfer of responsibility constitutes 'legal channelling' (Trebilcock and Winter, 1997) and is consistent with the world-wide trends relating to third party liability for nuclear incidents (Ameye 2010). Limitation periods will increase also with an extended limit of 30 years for death and personal injury and 10 years for other claims ${ }^{6}$.

This paper reviews just one area of change introduced by the 2016 Order, namely the type of damage for which compensation may be claimed under the 1965 Act and the relationship of this notion of damage with that both governed more generally by English common law and by EU law more specifically in the field of environmental liability ${ }^{7}$. The issue of compensation has been of interest to international lawyers for some time, especially in the context of the Chernobyl disaster (Barron 1986, Levy 1987). The 'labyrinthine' international regime (Swartz, 
2016) in this complex area has developed in response to the limitations of "ordinary common law" (OECD Nuclear Energy Agency 2016). The tort law constraints have been highlighted by the UK Government during the consultation on the 2016 Order (DECC 2011). Historically, the 1965 Act has governed claims for personal injury or property damage arising out of a nuclear incident. To these traditional heads of damage are added three new related categories of compensation, These are payable in respect of: (i) the cost of measures of reinstatement related to the impaired environment; (ii) loss of income deriving from a direct economic interest in any use or enjoyment of the environment; and (iii) the cost of preventive measures (including measures taken in response to a threatened occurrence, or an "event") and any damage caused by such measures. ${ }^{8}$ These form an exclusive remedy where breach of the statutory duties under the 1965 Act has occurred through which liability is channelled to the operator as defendant (Thomas and Heffron, 2012). The provisions of the 1965 Act concerning the right to compensation are now subject to consequential amendments to accommodate these additional categories of claim. ${ }^{9}$

This paper will explain these changes to the liability regime for nuclear installations before reviewing the traditional heads of damage under the 1965 Act. It argues that, while there is some welcome clarification of what amounts to an 'occurrence' the purposes of the 1965 Act, disappointingly little else has been done to clarify concepts of personal injury and property damage for the purposes of the Act. As things stand, such concepts sit alongside traditional tort notions of injury and damage leaving the law highly dependent on earlier, but not always consistent, case law. The paper then goes on to consider the impact of the new categories of compensation, introduced by the Order, evaluating the extent to which these draw upon EU law structures for environmental impairment liability. Here too we argue that given limited jurisprudence on liability under the Environmental Liability Directive, the precise extent of liability is open to doubt. Before turning, then, to the main theme of compensation for harm caused by nuclear incidents, the next section offers a short introduction to the recent changes made to the liability regime.

\section{Changes to the liability regime for nuclear installations}

The Paris and Brussels Conventions allow caps on the liability of an operator arising out of any individual incident which results in nuclear damage (Faure and Borre, 2008). In the UK, an operator will include all licensees operating the licensed site under a nuclear site licence. The 2016 Order raises the liability coverage limit of an operator of a licensed installation from $€ 170$ million to $€ 1,200$ million per incident. Liability is tiered so that, within the first tier, the operator is strictly liable up to a figure of $€ 700 \mathrm{~m}$. Thereafter the operator is liable for the next $€ 500 \mathrm{~m}$ rising in annual increments of $€ 100 \mathrm{~m}$ over five years. The final tier of $€ 300 \mathrm{~m}$ is payable from public funds, contributed by all contracting parties to the Brussels Convention. ${ }^{10}$ In addition to these operator caps, there is a limit of $€ 80 \mathrm{~m}$ for incidents caused by nuclear materials in transit and the regime is extended to cover installations for disposal of nuclear material with an enabling power for the Secretary of State to set caps on liability. As mentioned above, the limitation period for lodging a claim with respect to loss of life or personal injury is extended from ten years to 30 years. All other claims are subject to the original limitation period of ten years from the date of the incident ${ }^{11}$. 
As originally enacted, the 1965 Act did not extend to nuclear incidents occurring or damage suffered in a non-contracting state. Under the amendments to the $1965 \mathrm{Act}^{12}$, the range of potential claimants now includes those located in states that have no nuclear installations on their territory at the time of the nuclear incident. States may also bring claims if they have in place, at the time of the incident, national nuclear liability legislation, which affords equivalent reciprocal benefits; based on the principles of the Paris Convention. Therefore, claims brought by claimants domiciled in non-Convention States, affected by a nuclear incident in a Convention State such as the UK may bring a claim under the 1965 Act regime. This would include, for example, a claimant domiciled in Ireland, which is a non-nuclear (and a non-Paris Convention) State, who suffers damage from a UK--based nuclear incident and pursues a claim in the English courts. However, it remains possible for such a claimant to lodge a claim, for example in tort, in the Irish courts. Not only would this not be subject to the liability caps but it would work outside the channelled strict liability of the operator so that contractors or other potentially liable third parties could be sued.

\section{The existing heads of damage: personal injury and property damage}

The 1965 Act creates a liability regime, applicable to operators of nuclear licensed sites, which imposes strict liability for injury or damage caused by a nuclear occurrence, and it requires operators to have in place insurance or other cover to align with the liability limits outlined above. Under the Convention on Supplementary Compensation for Nuclear Damage, ${ }^{13}$ nuclear damage means that the loss or damage must have been caused by ionising radiation emitted either in the operator's nuclear installation or during the transport of nuclear substances to or from the installation. However, nuclear damage can arise from "the radioactive properties of such matter, or from a combination of radioactive properties with toxic, explosive or other hazardous properties of such matter.",14

This leaves open, nonetheless, the question of what constitutes property damage for the purposes of the Act. This concept of property damaged by an escape of contaminants is well understood in the law of negligence and of nuisance (Smith, III, $1995)^{15}$ but we wish to argue that it can be problematic to apply common law principles of physical damage to the consequences of a nuclear accident (Lee, 2000). Since the 1965 Act tends to take for granted the concepts of damage or at least rely on common law understandings of heads of damage, we are left with uncertainty as to the extent of compensation in the nuclear regime.

Clearly land may be the subject of direct physical damage or damage may be caused by encroachment upon or in certain nuisance/negligence claims by literally undermining the land, or by some other form of direct physical injury to the land itself or to property on the land. In negligence, to establish liability for property damage, the claimant landowner will need to establish that the defendant owed a duty of care which was breached when the defendant failed do something which a reasonable landowner would ordinarily do or did something which a reasonable landowner would not do. Historically, in nuisance, where a neighbouring party is responsible for direct injury to land there may be little reason to enquire as to the utility of the conduct of that party since everyone is bound 'to use his property in such a manner as not to injure the property of his neighbour ${ }^{16}$. In effect, the courts may look to the fact of the 
damage in determining that there has been unreasonable interference with the enjoyment of land. ${ }^{17}$

Beyond physical encroachment and (indirect) physical injury to land, Lord Lloyd in Hunter $v$ Canary Wharf added a third category of damage in nuisance which he labelled interference with quiet enjoyment of land, but which is often referred to as 'amenity loss' (McBride and Bagshaw, 2015). Here, in the absence of direct physical intervention, and in the realm of "physical discomfort" it is usually necessary to show that the activity on neighbouring land, creating the nuisance, is unreasonable in the particular locality. ${ }^{18}$ Note however that this category of amenity loss actually takes two forms. It can give rise to a clear diminution in the amenity value of the property throughout the period within which the nuisance exists. If this is true, then recovery of damage for diminution in such value maybe possible. This must now be contrasted with the situation in which, although there is inconvenience and annoyance, there can be no proof of loss in the amenity value of the property. In such cases no damages will be recoverable either at common law or within the meaning of damage to property in section $7(1 \mathrm{~A})(\mathrm{b})$ of the 1965 Act. $^{19}$

This means, that in relation to direct physical injury or amenity loss, the appropriate sum in damages will then be such as to compensate: in the first category, for any physical damage to the land together with any consequential losses flowing from this; and, in the second category, any diminution in amenity value of the property for so long as the nuisance persists. In Hunter, Lord Hoffmann puts it this way.

“The land has not suffered 'sensible injury', but its utility has been diminished by the existence of the nuisance. It is for an unlawful threat to the utility of his land that the possessor or occupier is entitled to an injunction, and it is for that diminution in such utility that he is entitled to compensation. $" 20$

There will be cases in which the land has indeed suffered 'sensible injury', though determining quite what this constitutes is by no means obvious (Witting 2002). ${ }^{21} \mathrm{~A}$ useful starting point for considering this issue in relation to the 1965 Act is the case of Merlin v British Nuclear Fuels Plc ${ }^{22}$ which involved a claim for diminution in value of a house in Ravensglass in proximity to the Sellafield Plant operated by British Nuclear Fuels. The Merlins were unable to sell their house following its appearance in a television documentary which indicated that the house was adversely affected by radioactive contamination. There were heightened levels of radioactivity around the house, which, the Merlins alleged, and BNFL accepted for the purposes of the case, originated in waste emitted from the Sellafield Plant. The action by the plaintiffs involved a claim that the defendants had breached their duty under section 7(1) of the Nuclear Installations Act 1965. This imposes a duty to guard against any occurrence involving nuclear matter or ionising radiation emitted from any waste discharge so as to cause injury to any person, or damage to any other property. Because the case involved a statutory claim under the 1965 Act, there are questions about the applicability of the judgment to common law claims in tort. Certainly claims at common law seem thereafter to have taken a more extensive approach.

The case did involve certain questions of potential personal injury but while the Merlins and their children may have feared heightened levels of risk, particularly risks of cancer induced by the inhalation or ingestation of the radionuclides, there was no 
immediate evidence of any illness or harm having befallen the family. The issue became, therefore, whether the presence of radionuclides within the house, that is contained by the walls, ceilings and floors of the property itself, constituted damage. Although there were some questions of causation relating to the conduct of the plaintiffs and to the impact of the television documentary, in broad terms there was little doubt that the impact on the house had rendered it less valuable and clear economic loss resulted. The question was whether those economic losses were consequent upon any physical damage to the property.

Gatehouse J rejected 'the argument that the contamination at the plaintiffs' house per se amounts to damage to their property. All that such contamination as was admitted in this case amounts to is some increased risk to the health of its occupants". ${ }^{23}$ As such, and not yet having suffered any health effects, the Merlins had no damage upon which to found the claim under s 7 of the 1965 Act (Wakeford et al., 1989). Lest one would wish to confine this decision to the narrow basis of a claim under the Nuclear Installations Act, it should be said that "damage to property" under that Act is not defined, so there is no necessary reason to believe that the definition in the 1965 Act was particularly more restrictive than any definition at common law. However, the Merlin case must be considered in the light of a later case concerning radioactive contamination, namely Blue Circle Industries Plc v Ministry of Defence. ${ }^{24}$

The Blue Circle case also involved the migration of radioactive material, in this case from the Atomic Weapons Establishment at Aldermaston. This washed out onto the land of the plaintiff following heavy rainfall. An area of marshland on the claimant's land, a large Victorian 'Manor House' which operated as a conference centre, was contaminated as a result. Decontamination work was carried out by the Ministry of Defence at its own cost. As it happened, around this time (in 1993) there were negotiations for the sale of the conference centre. Once the fact of the contamination was disclosed; negotiations fell through and from a possible sale of $£ 10.35 \mathrm{~m}$ in April 1993, by the date of trial, the judge estimated the value of the estate at around about $£ 5 \mathrm{~m}$. Questions of the calculation of loss are dealt with below but before moving to that point, it is necessary to review the treatment of Merlin in the Blue Circle case. In giving judgment in Blue Circle Aldous LJ examined the wording of s7 of the 1965 Act and stated that it was not limited to particular types of damage:

"Damage within the Act will occur where there is some alteration of the physical characteristics of the property, in this case the marshland, caused by radioactive properties which render it less useful or less valuable."25

This has become the accepted notion of property damage for the purposes of the 1965 Act. The court had little hesitation in stating that the plutonium in the Blue Circle case had "intermingled" with the soil in the marsh to such an extent that it could not be separated from the soil by any practical process, necessitating remediation by the removal of the soil:

"I have no doubt that the addition of plutonium to the topsoil rendered the characteristics of the marshland different." 26

This obviously raises the question of how this sits alongside the decision in Merlin. In answer to this question his Lordship stated: 
"In Merlin's case the dust was in the house and the judge did not hold that the house and the radioactive material were so intermingled as to mean that the characteristics of the house had in any way altered.",27

His Lordship does go on to say that "there is no need to decide whether Merlin's case was rightly decided" 28 on the basis that the cases were distinguishable on their facts. It may be that a more satisfactory way of distinguishing these cases is not merely on the basis of the intermingling of the waste material as such but because such material lost to the soil should be taken as discarded for the purposes of Directive 2008/98/EC (the Waste Framework Directive) such that there could be a regulatory requirement for remediation under both EU and English law. ${ }^{29}$

If the basis of the distinction alone is the degree of intermingling of the material, this particular point of distinction must be open to some doubt, especially following the decision of the House of Lords in Hunter $v$ Canary Wharf. ${ }^{30}$ Amongst the nuisances of which the residents of the London Docklands complained in this case, occurring at the time of the building of Canary Wharf, was the deposit of dust within their properties. This raised the issue as to whether this might be taken to constitute physical damage (such as to give right to an action in negligence) rather than a mere amenity loss in nuisance. The Court of Appeal seemed happy to accept that excessive deposits of dust, above and beyond that which might ordinarily be expected ${ }_{2}$ could amount to or at least constituted a cause of damage, and that this will be particularly so where professional cleaning was required, or where the dust caused a physical change in the article which was affected, making it less useful or less valuable. On appeal, the House of Lords do not seem to have disputed or questioned this finding in of the Court of Appeal.

On the facts of Merlin, radionuclides were present in the dust in the carpets of the house, just as construction dust had affected the residents' carpets in the London Docklands. Given the risks posed, some specialist cleaning along the lines suggested by the Court of Appeal would hardly seem inappropriate in Merlin and the interference might be deemed 'excessive' within the terms suggested in Hunter. Even allowing for a possible distinction between the contamination in Merlin and that in Blue Circle on the basis of regulatory requirements for remediation, it nonetheless seems that, in the aftermath of the Hunter case, the Court of Appeal in Blue Circle took a much less restrictive view of damage than did Mr Justice Gatehouse in the Merlin case. To some extent this is supported in a later case under section 7 of the Nuclear Installations Act 1965, arising out of Scotland, in which the analysis in Merlin fell to be considered.

In Magnohard Limited $v$ United Kingdom Atomic Energy Authority (UKAEA) ${ }^{31}$ the petitioners owned property alongside the UKAEA power station at Dounreay in the north of Scotland. The first petitioner was a family company which owned an estate including a beach and fishing rights and it was joined in the action by various other petitioners living close by. The damage of which the petitioners complained was in the form of the presence of particles of nuclear matter on the beach. It is thought that the particles are deposited somewhere at sea, and drawn in by wind and tide to the beach. The first petitioner argued that the presence of such particles represented 
damage to its land, and the remaining petitioners, local residents, brought claims for "anxiety and stress" 32 arising out of the presence of the particles.

In this initial action, although the petitioners reserved their right to seek further remedies in the future, they sought the following remedies:

- a declaration that UKAEA are failing to perform their statutory duty under s7 of the Nuclear Installations Act 1965; and

- an interim order requiring UKAEA to implement a programme of monitoring and clean-up.

Initially the claimants had sought also a declaration that UKAEA had failed to act in compliance with Article 8 and Article 1 Protocol 1 of the European Convention on Human Rights, but it was agreed that these arguments would not be pursued at this preliminary stage.

The judgment in the case offers a long history of activity at Dounreay. However, the essential issues might be summarised very quickly. The reprocessing of nuclear fuel at Dounreay had ceased. Routes by which radioactive particles might escape were thought to have been closed off. Nonetheless, it is accepted that particles of nuclear matter constituting radioactive waste continued to come ashore onto on Sandside Beach. It seems inevitable that these particles had escaped from the Dounreay site, although the date on which and the route by which such escape took place is a matter of speculation. The first particle on the beach was detected in 1984. Nothing was found then until 1997 when two further particles were found. In the four years between 1999 and 2002 the particles found were five, six, three and five respectively. However, following the first hearing on 24 February 2003, an eight-week period of monitoring took place. This led to the discovery of 16 further radioactive particles.

The first issue to be determined under the application was whether the petitioners were correct in commencing the action by way of judicial review under section 45(b) of the Court of Session Act 1988. This states that:

"The Court may on application by summary petition...

(b) order the specific performance of any statutory duty, under such conditions and penalties (including fine and imprisonment, where consistent with the enactment concerned) in the event of the order not being implemented, as to the court seem proper."

Counsel for UKAEA argued that judicial review was restricted to applications where the matters raised involved the exercise of administrative decision-making powers and where the exercise of that power was challenged. As such, Counsel argued that this was an inappropriate remedy to ensure compliance with s7 of the Nuclear Installations Act 1965, which placed upon UKAEA a duty to secure that no occurrence using nuclear matter causes injury to any person or damage to any property arising out of the radioactive properties of the nuclear matter. Essentially the argument pursued by counsel for UKAEA was that the supervisory jurisdiction of the Court concerned the manner in which power had been exercised. The Court would intervene where a wellrecognised complaint about the manner of the power being exercised could be made 
out. ${ }^{33}$ But to seek to enforce the statutory duties of UKAEA by resort to judicial review dragged the Court, it was argued, into consideration of the merits of the decisions taken by the authority. ${ }^{34}$

In giving judgment, Lady Paton rejected this argument. In her view:

"An application for specific performance of a statutory duty is a longestablished remedy, quite separate from an application to the general supervisory jurisdiction of the Court. I also agree that this separate remedy has been incorporated within the judicial review procedure for administrative reasons." 35

As we have seen above, the petitioners did not seek, at this time, any order based upon human rights arguments. This may well have been because of questions of fair balance between wider community interests and individual interests together with associated arguments concerning the margin of appreciation. Nonetheless, they reserved their rights to proceed on the basis of human rights legislation following the conclusion of the interim applications.

In response UKAEA suggested that arguments based on the European Convention on Human Rights (ECHR) were irrelevant. This was because the first petitioner suffering damage was not a natural person so as to give rise to rights under Article 8 of the ECHR. On the other hand, the other petitioners could show no evidence of actual injury such as to found a case akin to that of Lopez Ostra $v$ Spain. ${ }^{36}$ As for Article 1 of the First Protocol to the Convention, only the first petitioners could show the presence of particles on their land. Even then, Counsel for UKAEA argued that this did not amount to damage to the land (see below) leaving only a claim for economic loss which was insufficiently severe to amount to any form of expropriation under human rights law. Lady Paton did not respond to these human rights arguments in any great detail given the preliminary stage of the proceedings. Nonetheless she refused to exclude the possibility that there could be a case to answer in respect of one or more breaches of the ECHR. Thus she refused to rule this out as irrelevant, and allowed that the parties could adjust their pleadings and make further submissions in any later stage of the case. In the event, no such case came to a full hearing before the court.

In relation to any personal injury, section 26 of the 1965 Act defines injury as including "personal injury and includes loss of life". There was no question of physical injury in these claims and Lady Paton cited Merlin as authority for the proposition that the 1965 Act was not intended to compensate for the risk of future injury. As is shown below, it was accepted that the beach contamination might give rise to fear of injury and it was accepted that identifiable psychiatric or possibly psychological illness which was caused by a wrongful act might be recoverable even if the common law had always restricted such claims as a matter of policy. Although Lady Paton accepted that stress and anxiety could be caused to those living in the vicinity of nuclear installations, where the 1965 was breached, she nonetheless felt that, of necessity, the law must limit such claims.

This element of the judgment mirrors the later decision of the House of Lords in Grieves $-v-F$ T Everard \& Sons $^{37}$, a case in which workers developed pleural plaques 
following exposure to asbestos. The pleural plaques were said not to constitute damage as the appellants manifested no-neither symptoms nor health effects, and faced neither greater-heightened susceptibility susceptibilities to other disease nor shortening of life expectancy. Arguments that anxiety about the presence of the plaques and increased risk of future asbestos related injury were equally ruled out as a species of damage; neither the pleural plaques nor the anxiety itself represented damage in law either singly or in combination. Finally, the appellant Grieve had developed psychiatric injury as a result of this anxiety but this claim too was dismissed on the basis that the risk represented by the plaques would not cause psychiatric injury in a person of reasonable fortitude. Arguments that the psychiatric injury was consequent on foreseeable physical injury ${ }^{38}$ were rejected on the basis that the foreseeable physical injury (asbestos related disease) had not occurred; Grieve simply worried that it might occur.

Magnohard is consistent with this later ruling and with the earlier line taken in Merlin $^{39}$ that the presence of radionuclides, even in the bloodstream, may increase the risk of cancer but does not amount to personal injury per se. However, Lady Paton stressed that although she was not persuaded that there had been injury for the purposes of s7 of the Nuclear Installations Act 1965, where elements of the claim were not based on the 1965 Act, as with the human rights claims, questions of stress and anxiety may still remain relevant considerations in the claims. Moreover, in this context, changes to the limitation period within which claims can be brought are significant. The earlier limitation period under the Paris Convention restricting the right to claim for compensation to within ten years from the date of a nuclear incident has been extended by the Amending Protocol to 30 years in the case (only) of claims for personal injury. This change is introduced by amendments to the limitation regimes in sections 7 to 11 of the 1965 Act by Article 17 of the 2016 Order and means that, if fears materialise and cancer does result from exposure, there is a greater likelihood of a claim.

\section{What amounts to an occurrence?}

There is one particular issue in Magnohard which relates to the changes introduced by the 2016 Order and this concerns the use of the word 'occurrence' in section 7 of the 1965 Act. This is a word commonly used in insurance contracts (Richardson, 2002) so that its meaning and its clarification in the amended 1965 Act is of potentially wider significance (Abraham (1988). The section imposes a statutory duty to secure that no occurrence involving nuclear matter causes injury to any person or damage to any property, but the word "occurrence" has never been defined for the purposes of s7 of the Act. It is clear from the wording of the Act that what is required is not merely that there is no occurrence, but that there is no occurrence causing injury or damage. In Magnohard, Lady Paton consulted the Oxford English Dictionary definition of "occurrence" finding:

"something that occurs, happens, or takes place; event, incident."40

In her Ladyship's view, the word "occurrence" could apply to at least two situations on the facts of the case, namely the arrival of a radioactive particle at Sandside Beach, and also the remaining of the particle on the beach in the sense that this is something which "takes place". It followed that when particles arrive or remain on the beach 
there was said to be "an occurrence involving nuclear matter"41 for the purposes of s7 of the 1965 Act. This does not resolve, however, the question as to whether that occurrence causes injury to person or damage to property. The petitioners pointed out that either personal injury or property damage would be sufficient for the purposes of s7 liability. It followed that if the Court took the view that there was damage to property, the question of whether there was injury to person was academic. Nonetheless, as shown above, counsel for the petitioners did argue that injury to persons existed. The Scottish Environmental Protection Agency accepted that ingestion of particle or contact with the skin could cause injury. This was said to be different to the radioactive contamination in earlier cases such as Merlin or Blue Circle. In both of those cases there had been no suggestion of actual physical injury. Here the presence of that risk did give rise to rational fear of injury causing stress and anxiety albeit that no actual physical injury was demonstrated.

That left the question as to whether there had been an occurrence causing damage to property. Lady Paton judged that Sandside Beach had suffered physical damage in that there was a physical change to the area along Blue Circle principles, which had fundamentally altered its physical characteristics. This was caused by the presence of particles with radioactive properties. Damage was said to occur as soon as the radioactive particles were deposited on the beach. Moreover, restriction of the use of the beach in consequence, together with warning notices placed on the beach, tyre track marks in the sand, and the removal of portions of sand were all evidence of a change in the physical characteristics of the land. This was not of a de minimis character. The judgment goes on to say that:

"The most immediate source of the radioactive particles is a sea-based cache, such that the deposit of radioactive particles can neither be predicted nor controlled, together with the fact that the UKAEA cannot guarantee either the size or the level of radioactivity of particles deposited, or that every radioactive particle deposited on the beach would be detected and removed. It seems to me that the Sandside Beach is subject to a particularly unpleasant type of contamination which cannot easily be cured, and which makes the beach unattractive to any potential user or purchaser.",42

This passage allowed the Court to distinguish Merlin, in that, in Merlin, no special equipment or cleansing measure was required to enable the householders to continue the use of their house. In contrast, the Sandside Beach could not be used without very particular processes of land management, which were "hardly standard or commonplace". ${ }^{43}$

Having found however that there was an occurrence involving damage caused by nuclear matter, the Court refused an order for specific performance. This was because the Court felt that s7 did not impose any clear statutory duty to monitor or to cure or clean-up any damage caused in breach of the section. The Court felt that clearer wording in the statute would be necessary before it was appropriate for a court to order specific performance of a statutory duty. However, the Court was willing to give a declaration in favour of the first petitioners that: 
"UKAEA have failed and are continuing to fail to perform their statutory duty under s7 of the Nuclear Installations Act 1965 to secure that no occurrence involving nuclear matter causes damage to any property of any person..."44

This was said to be an accurate statement of what was being allowed to happen and the court was willing to give a formal legal acknowledgement that this was the case.

The notion of a 'cache' of radioactive particles which might over time migrate has proven problematic in practice. Potential liability for such a cache might inhibit the effective transfer of operational facilities or of land where, as is often the case, new build is taking place alongside former nuclear facilities (Temple et al, 2006). Not only is there a fear that incoming operators might face liability but if each deposit of radioactive particles constitutes an occurrence in the manner suggested in Magnohard, the limitation clock will be reset on each occurrence giving rise to very long tail liability particularly now that limitation periods are extended. The 2016 Order seeks to reverse the Magnohard view and limit liability to those operators responsible for the initial release of radioactive material. In the words of the Order,

'if nuclear matter is in a place at a particular time as a consequence of an occurrence falling within section 7(1B) (including section 7(1B) as applied by section $7 \mathrm{~B}, 8$ or 9$), 10(1)$ or 11$)$, neither the presence of the matter in that place at that time nor any effect that the matter produces at that time is to be treated as a separate occurrence falling within any of those provisions'. ${ }^{45}$

This is a clarification which will be welcomed by the nuclear industry which worried that long-tail, legacy liability might hinder decommissioning and sale of facilities. Driven by commercial considerations, it is however an isolated example in the Order of an opportunity taken to clarify liability for personal injury and property damage caused by nuclear incidents. Elsewhere the Order seems content to leave the law dependent on existing case law, which, we have tried to show, is already overworked and obscure.

\section{New categories of damage}

While as originally drafted, the 1965 Act simply covered personal injury and damage to property, the 2016 Order, in line with the amending protocols, modifies the Act to introduce new categories of damage, which potentially extend the strict liability of operators (Tetley, 2006) There is no priority given to claims for different types of damage so that claims under the scheme are paid out on a 'first come, first served' basis. Because, as we shall see, compensation is available to re-instate the environment, there is a possibility of double compensation if damages are paid out for property damage but never deployed for that purpose, if at a later date the land is subject to re-instatement by a public authority. Section 13A(2) of the 1965 Act therefore allows that the court in determining the person's claim in respect of damage to property must take into account, as affecting the amount of the person's loss, any benefit or loss that arises from or in connection with measures of reinstatement.

The cost of re-instatement measures is the first of the new categories of compensation where the environment has been impaired. The second is the loss of income deriving from a direct economic interest in the use or enjoyment of the environment. The final 
category is the costs attaching to preventive measures together with any further loss or damage caused by such measures. For the first two of these categories some element of environmental impairment is necessary. Significant environmental impairment is not defined except that section 26(1) states that it does not include damage to the environment which is not sufficiently significant 'to be eligible for compensation under the Act as damage to property, whether or not the part affected is property in respect of which such compensation can be sought'. It may well be therefore that the Blue Circle notion of 'some alteration in the physical characteristics of the property which render it less useful or valuable' will be employed as a measure of whether impairment has taken place. It may remain necessary to judge whether the degree of impairment is then significant for section 26 tells us what is not significant but not necessarily which eligible damage may then be regarded as significant.

Looking at these categories in turn and in reverse order, preventive measures refer to measures taken after a nuclear incident which has created a 'grave and imminent threat of nuclear damage ${ }^{46}$. Such measures should be reasonable (in the words of section $11 \mathrm{H}$, 'appropriate and proportionate in the circumstances') and aimed at preventing or minimising nuclear damage. The amended Convention allows that competent authorities might approve such measures but the transposition into section $11 \mathrm{H}$ of the 1965 Act does not make provision for this. Given the multiplicity of necessary actions in the aftermath of a nuclear incident and the urgency which may attach, this seems sensible. Because all recoverable costs and compensation depends on a breach of duty by a licensee, for the avoidance of doubt, a duty is placed upon licensees to secure that no event arises which would create a grave and imminent threat of a breach of the other duties imposed by section 7 of the 1965 Act: ${ }^{47}$

In relation to the second (middle) category of damage, it was apparently always the intention of the Act (Tromans, 2010) to make provision for compensation in the event of economic losses which are consequential upon damage to a property interest' subject to rules of remoteness of damage, rather than for simply pure economic loss. The Amending Protocols now add as an independent category of damage economic loss consequent upon damage to person or property but the Order makes no amendment to the Act, given the width of existing coverage of consequential losses. However, a new category of recovery for losses which are purely economic now arises where, following a nuclear incident, there is loss of income from an economic interest in any use or enjoyment of the environment. This category can only apply where the loss of income suffered is somehow not covered by the award of compensation recovered for personal injury and damage to property. A new section $11 \mathrm{G}$ makes provision for compensation for certain classes of existing enterprises (though not employees) who would lose income ${ }_{2}$ derived from directly ${ }_{2}$ lawfully exploiting environmental resources, due to environmental impairment caused by a breach of the 1965 Act duties. Thus losses from fishing or shellfish harvesting or the loss of pasture on common land for hefted stock might all be covered under this head where the claimant can show that this activity was being lawfully pursued up until the time of the incident (Salter,2015).

In relation to the first category of re-instatement, there is some experience of what this may include by reference to concepts in the EU Environmental Liability Directive (ELD). ${ }^{48}$ The purpose of the Directive is to establish a framework of environmental liability based on the "polluter pays" principle and the stated aim is to prevent and 
remedy environmental damage. Environmental damage in this context carries a particular definition and breaks into three parts:

- Damage to protected species and natural habitats under EU law ${ }^{49}$ where such damage poses problems in reaching or maintaining favourable conservation status as a result of significant adverse effects. Nationally designated species and habitats may also be included under this head at the discretion of Member States.

- Water damage creating significant adverse effects upon the status or ecological potential of a water body as defined under the Water Framework Directive.

- Land contamination carrying a significant risk to human health as a result of introduction of substances preparations organisms or micro-organisms in, on or under land.

All three of these heads can be taken to constitute 'significant environmental impairment', though the third and sometimes the second of these might equally well covered by existing notions of damage to property. Section $13 \mathrm{~A}(2)$ therefore allows that a court in determining a claim for damage to property must take into account any gains or losses that result from measures of reinstatement. Equally, this is eoveringapplication is to property in what might be regarded as the unowned environment. In the insurance case of Bartoline $v R_{S A}^{50}$ a distinction was drawn between claims for damage to private property and costs attaching to the remediation of environmental damage in the wider public interest (Thornton, 2007). Thus damage to protected species and habitats in the unowned environment will be caught where there is impairment of the environment if, in accordance with section 26(1), the damage caused would have been sufficient to have allowed recovery, if the species or habitats in question had constituted owned property.

A strict liability system for the prevention or remediation of significant harm caused by operational activity is a familiar concept, the ELD having been transposed in England effective from 1 March 2009. ${ }^{51}$ Annex III of the ELD lists a broad range of occupational activities (largely activities subject to industrial pollution controls under EU laws) within its remit. Nuclear installations are not included in Annex III activities (Tromans, 2010) because, as Article 4(4) of the ELD makes clear, nuclear incidents are covered by the relevant international conventions. ${ }^{52}$. Strict liability for environmental impairment attaches to Annex III activities attracting responsibility for remediation of that damage irrespective of any fault or negligence on the part of the operator. A fault based liability regime applies to other occupational activities where these cause damage to protected species and natural habitats. Here the amendments made by the Order are modelled to some degree on strict liability under the ELD. However, there is surprisingly little case law as yet under the ELD so a number of questions relating to the nature of damage remain open. For example in a recent case $^{53}$, the High Court ruled that damage was restricted to deterioration of the environmental situation and could not include the prevention of an already damaged environment from regenerating. That case as well as the main case to reach the $\mathrm{CJEU}^{54}$ relates particularly to the date of damage, an issue less likely to be pertinent in relation nuclear incidents. With some exceptions, this is true for many European jurisdictions in which 'cases remain rare and sometimes non-existent in some countries', which, when combined with the 'imprecise language of the ELD' has 
given rise to a 'patchwork' of liability systems (Bio Intelligence Services, 2013). This is hardly a promising start for the legislative base of an international liability regime for nuclear incidents.

Annex II of the ELD deals with remediation and places the burden upon the operator to propose remediation options. The competent authority will then determine the appropriate remedial option for the site in question. The amended 1965 Act now follows this pattern. Section $11 \mathrm{~A}(1)$ allows that in the event of significant environmental impairment, 'a qualifying public authority may make a claim under this Act for compensation in respect of the reasonable cost of relevant measures of reinstatement relating to that impairment.' Under the ELD, where there is damage to water or to protected species and/or natural habitats the options should be based around the following remedial concepts:

- primary remediation in order to return the site to its baseline condition;

- complementary remediation consisting of off-site measures in situations in which primary remediation will not have the effect of returning the site to its baseline condition; and

- compensatory remediation to account for the 'interim' losses of natural resources and services in the period until the recovery of the site takes effect.

The above concepts do not apply in the case of land damage. In such situations, the task is to ensure that the land ceases to pose any lasting threat to human health. The operator should take therefore such measures as are necessary to achieve this.

Under the revised regime of the 1965 Act, no such distinction is made between water and land. It is clear that impairment of the marine environment is contemplated as section $11 \mathrm{~A}(7)$ states that any reference to 'environment' should be taken to cover the 'environment within the territorial limits of the United Kingdom, in or above the exclusive economic zone of the United Kingdom or on the continental shelf of the United Kingdom.' Primary restoration of the environment so defined is clearly covered but it is less obvious whether complementary or compensatory remediation is covered. Section $11 \mathrm{~A}(5)$ provides that a measure of reinstatement may include reinstating or restoring not only what has been destroyed or damaged in the environment, but also a measure 'establishing the equivalent of what has been destroyed or damaged in the environment.' Although we are told that any such measure must be 'appropriate and proportionate ${ }^{55}$ there is no definition of equivalence. It may be hard to see how compensatory damages, to account for interim losses as envisaged in the ELD, can be said to constitute a measure of re-instatement. The Government's response to this issue in consultation was that the amendments would 'not expressly include compensatory remediation' (DECC 2012, 4). This does not seem to entirely rule out the possibility of such payments but it would seem that complementary remediation is what is intended by this mention of equivalence and that the cost of this would be recoverable in principle. 
In a sense, it may have been felt that there was no need for any definition of equivalence since there is an elaborate regime to determine whether or not a scheme reinstatement is approved under section 11B of the 1965 Act. A claim must be made by a qualifying public authority. ${ }^{56}$ A public authority will qualify for these purposes if ordinarily in discharge of its functions it would 'take, or arrange for the taking of, measures of reinstatement relating to that impairment of the environment. ${ }^{57}$ In respect of a UK claim, this could clearly include the Environment Agency in England, or its equivalent in devolved administrations, as well as local authorities, both having powers to combat environmental impairment ${ }_{2}$ for example under the contaminated land regime. ${ }^{58}$ There is a further category of qualifying public authority, however, whose functions include paying costs incurred by another public authority in reinstating the impaired environment. The most obvious authority here is the Secretary of State since (for example) under the contaminated land regime the Government ultimately underwrites the polluter pays principle in the event that no appropriate person can be found. This is problematic in that it is the Secretary of State who is charged with the approval of any measure of reinstatement. This may mean that the Secretary of State could end up potentially approving a claim lodged by government. This conflict is recognised in the Act and section 11B allows and independent person to approve reinstatement measures in such circumstances. Curiously, however, it is for the Secretary of State to appoint the independent person. The fact that the courts can review any determination under an appeal procedure contained in section 11D presumably rescues any such arrangement from breach of Article 6 of the European Convention on Human Rights ${ }^{59}$.

There is one final amendment to the 1965 Act which indicates how closely the provisions of reinstatement of environmental impairment are modelled on the ELD. This is in the form of section 11C which allows representations to be made to the Secretary of State in respect of measures of reinstatement for which approval is sought by an application under section 11B. The persons entitled under the Act to make such representations are the person whose breach, or alleged breach, of a duty (allegedly) caused the impairment of the environment, together with persons with an interest in or right over property affected by reinstatement measures such as would entitle that person to claim for damage to property. The Secretary of State may also invite other persons to make representations as regards the measures of reinstatement. The latter provisions begin to look similar to requests for action under the ELD whereby third parties with a sufficient interest in a particular site of damage may request formally that the competent authority take action. Under the Directive, requests must be supported by evidence of the environmental damage and response by competent authorities to requests should be the subject of review.

\section{Conclusion}

The 2016 Order in amending the 1965 Act spends a good deal of its energy laying down a framework for preventive action and for the operation of new categories of compensation for environmental impairment and its consequences. The ELD with its underpinning ideas of liability for environmental impairment has clearly formed a reference point in shaping the new regime. Unfortunately, however, core concepts within the ELD are open to contest across EU member states (Bio Intelligence Services, 2013), meaning that the new categories of nuclear liability may themselves be open to doubt. In terms of existing categories of loss arising through personal 
injury and property damage, however, much less energy is expended in clarifying the law beyond a more detailed explanation of what amounts to an occurrence for the purposes of section 7 of the 1965 Act.- This leaves us dependent on a limited body of case law, which itself is hard to interpret and arguably inconsistent. Given the missed opportunity for statutory enlightenment as to what constitutes damage to person and property in the event of nuclear accident, further clarification may need to come from case law. Nonetheless we must hope that further, future case law will be very limited indeed - for all of our sakes.

\section{$\underline{\text { References }}$}

Abraham K (1988) Environmental Liability and the Limits of Insurance 88(5) Columbia Law Review 942

Ameye Evelyne, (2010) 'Channelling of Nuclear Third Party Liability towards the Operator: Is it Sustainable in a Developing Nuclear World or is there a Need for Liability of Nuclear Architects and Engineers?' 19 (1) European Energy and Environmental Law Review 33

Barron, Jillian (1986) 'After Chernobyl: Liability for Nuclear Accidents under International Law' 25 Columbia Journal of Transnational Law 647

Bio Intelligence Service and Stevens \& Bolton LLP (2013) Implementation challenges and obstacles of the Environmental Liability Directive Final Report EU Commission, DG Environment, 16 May 2013

Coquillette Daniel, (1979) 'Muses from an Old Manse: Another Look at Some Historic Property Cases about the Environment', 64 Cornell Law Review 761

Department of Energy and Climate Change (2011) 'Implementation of changes to the Paris and Brussels Conventions on nuclear third party liability: a public consultation' (DECC, London):

$<$ https://www.gov.uk/government/uploads/system/uploads/attachment_data/file/42743 /1182-cons-implement-changes-paris-brussels.pdf $>$

Department of Energy and Climate Change (2012) 'Implementation of changes to the Paris and Brussels Conventions on nuclear third party liability: summary of responses and government response' (DECC London)

https://www.gov.uk/government/uploads/system/uploads/attachment_data/file/42757/ $\underline{\text { 4874-parisbrussels-government-response-to-consultation.pdf }}$

Faure, Michael G. and Vanden Borre, Tom, (2008) 'Compensating Nuclear Damage: A Comparative Economic Analysis of the U.S. and International Liability Schemes 33 William and Mary Environmental Law and Review 219

Lee Maria (2000) 'Civil Liability of the Nuclear Industry' 12 Journal of Environmental Law 117 
Levy Richard E.(1987), 'International Law and the Chernobyl Nuclear Accident: Reflections on an Important But Imperfect System' 36 (1) Kansas Law Review 81

McRae, Ben (1998) 'The Compensation Convention: Path to a Global Regime for Dealing with Legal Liability and Compensation for Nuclear Damage', 61 Nuclear Law Bulletin 25

McBride Nicholas and Bagshaw Roderick (2015) Tort Law (Pearson, Harlow, $5^{\text {th }}$ Ed.)

Obayashi Y and Hamada K, (2016) 'Japan nearly doubles Fukushima disaster-related cost to \$188 billion' Reuters Environment 9 December 2016 available at: http://uk.reuters.com/article/us-tepco-fukushima-costs-idUKKBN13Y047

OECD Nuclear Energy Agency (2017) 'Paris Convention on Nuclear Third Party Liability’ (16 January 2017) < https://www.oecd-nea.org/law/paris-convention.html>

Richardson, BJ (2002) 'Mandating Environmental Liability Insurance' 12 Duke Environmental Law and Policy Forum 293

Salter I, (2015) Burges Salmon Guide to Nuclear Law $\left(2^{\text {nd }}\right.$ ed. Burges Salmon, Bristol),

Smith III, G. Nelson (1995) 'Nuisance and Trespass Claims in Environmental Litigation: Legislative Inaction and Common Law Confusion', 36 Santa Clara Law Review 39.

Swartz N (2016) 'The Impact of the Convention on Supplementary Compensation for Nuclear Damage' 12(2) University of Pennsylvania Asian Law Review, 312

Temple R.M, Penny C, and Sullivan M.A., (2006) 'Liability for Nuclear Incidents: Should the UK Now Follow the US Approach?' 18(3) Journal of Environmental Law 443

Tetley M (2006) 'Revised Paris and Vienna Nuclear Liability Conventions: Challenges for Nuclear Insurers' 77 Nuclear Law Bulletin 27

Thomas A \& Heffron RJ (2012) 'Third Party Nuclear Liability: The Case of a Supplier in the United Kingdom' Electricity Policy Research Working Paper Series, EPRG WP 1205. University of Cambridge

Thornton, J., 2007. 'Public liability insurance and the extent of environmental coverclaim under the Water Resources Act 1991: Bartoline Limited v (1) Royal \& Sun Alliance Insurance plc (2) Heath Lambert Limited' Journal of Water Law 18(3), 99

Touitou-Durand F (2010) 'The Convention on Supplementary Compensation for Nuclear Damage: A Solution for Europe?' In: Pelzer N (ed) Europäisches Atomhaftungsrecht im Umbruch, Tagungsbericht der AIDN/INLA-Regionaltagung 2009 in Berlin, Baden-Baden, pp 257-274 
Trebilcock M and Winter R (1997) 'The economics of nuclear accident law' 17(2) International Review of Law and Economics 215-243

Tromans S (2010) Nuclear Law (2 ${ }^{\text {nd }}$ ed., Hart, Oxford)

Wakeford R, Binks K, Wilkie D. (1989) 'Childhood leukaemia and nuclear installations.' Journal of the Royal Statistical Society Series A 1989; 152:61-86.

Witting Christian, 'Physical damage in negligence' (2002) 61(1) Cambridge Law Journal 189

Yasunari, T., Stohl, A., Hayano, R. S., Burkhart, J. F., Eckhardt, S., and Yasunari, T.:(2011) 'Cesium-137 deposition and contamination of Japanese soils due to the Fukushima nuclear accident,' Proceedings of the National Academy of Sciences of the USA, 108, 19530-19534,

${ }^{1}$ This international regime is effectively Western European as only Belgium, Denmark, Finland, France, Germany, Greece, Italy, the Netherlands, Norway, Portugal, Slovenia, Spain, Sweden, Switzerland, Turkey and the UK ratified the Convention. Both Austria and Luxembourg have signed the Convention but not yet ratified.

${ }^{2}$ SI 2016 No 562

${ }^{3}$ See the Protocol of 12th February 2004 which amends the Convention on Third Party Liability in the Field of Nuclear Energy of 29th July 1960, as amended by the Additional Protocol of 28th January 1964 and by the Protocol of 16th November 1982 (the "Paris Convention"); and (b) the Protocol of 12th February 2004 which amends the Convention of 31st January 1963 Supplementary to the Paris Convention, as amended by the Additional Protocol of 28th January 1964 and by the Protocol of 16th November 1982 (the "Brussels Supplementary Convention").

${ }^{4}$ The Convention on Third Party Liability in the Field of Nuclear Energy of July 29, 1960, as amended by the Additional Protocol of January 28, 1964 and by the Protocol of November 16, 1982.

${ }^{5}$ The Convention of January 31, 1963 Supplementary to the Paris Convention, as amended by the Additional Protocol of January 28, 1964 and by the Protocol of November 16, 1982

${ }^{6}$ See Article 17 of the 2016 Order

${ }^{7}$ Directive 2004/35/EC of the European Parliament and of the Council of 21 April 2004 on environmental liability with regard to the prevention and remedying of environmental damage

${ }^{8}$ See articles 3 and 7 to 10 of and Schedule 1 to the 2016 Order

${ }^{9}$ Article 11 of the 2016 Order

${ }^{10}$ And is available to claimants from Brussels Convention countries only

${ }^{11}$ See Article 17 of the 2016 Order

${ }^{12}$ Ibid, Article 23-24

${ }^{13}$ The Convention on Supplementary Compensation for Nuclear Damage was adopted on 12 September 1997 by a Diplomatic Conference held 8-12 September 1997, and was opened for signature at Vienna on 29 September 1997 at the 41st General Conference of the International Atomic Energy Agency.

${ }^{14}$ Ibid Article 1(6)

${ }^{15}$ Included here is the rule in Rylands $v$ Fletcher (1868) LR 3 HL 330 which is now firmly established as a sub-set of the law of nuisance, see Cambridge Water v Eastern Counties Leather [1994] 2 AC 264 and Transco v Stockport MBC [2004] 2 AC 1. The migration of contaminants from one parcel of land to another might also constitute a trespass historically.. However, given that most actions will be pursued in negligence or nuisance, those are the torts considered here.

${ }^{16}$ Per Justice Mellor in his directions to the jury in St Helens Smelting v Tipping 11 Eng. Rep 1483 (H.L. 1865) at 1484. Note that these directions were upheld on appeal by the House of Lords: for background see Coquillette Daniel, 'Muses from an Old Manse: Another Look at Some Historic Property Cases about the Environment', (1979) 64 Cornell Law Review 761,

${ }^{17}$ St Helens Smelting v Tipping (1865) 11 HL Cas 642

${ }^{18}$ Sturges $v$ Bridgman (1879) LR 11 Ch D 852

${ }^{19}$ Hunter v Canary Wharf [1997] 2 WLR 684; and see the judgment of Waller LJ in Dobson and others v. Thames Water Utilities Limited (No. 1) [2009] EWCA Civ. 28 to the effect that since Hunter posited 
damages based on diminution of notional rental value then: "If the house is unoccupied throughout the time of the (transitory) nuisance, has suffered no physical injury, loss of value or other pecuniary damage, and would not in any event have been rented out, we are unable to see how there can be any damages beyond perhaps the nominal." (at 34)

${ }^{20}$ [1997] AC 655 at 706

21 As used by Lord Westbury in St Helens Smelting (supra) sensible injury is not necessarily material damage but could constitute diminution in value of the property (1865) 11 HL Cas $642,650-52$.

${ }^{29}$ See Van de Valle v Texaco Belgium [2004] ECR 1-07613, Case C-1/03 and see Part 2A Environmental Protection Act 1990.

${ }^{30}[1997] 2$ WLR 684

${ }^{31}$ [2004] Env LR 19

${ }^{32}$ At 351

${ }^{33}$ Such as Wednesbury unreasonableness, ultra vires, breach of natural justice etc.

${ }^{34}$ While the scientific judgement of regulators is not as such immune to challenge, in the absence of manifest error, courts should avoid substituting their own view for that of an expert and be slow to enter into debate about scientific findings or challenge the merits of an expert decision; see $R$ (Campaign to End All Animal Experiments) v Secretary of State for the Home Department [2008] EWCA Civ. 417 and R(Assisted Reproduction and Gynaecology Centre) v Human Fertilisation and Embryology Authority [2002] EWCA Civ. 20

${ }_{35}^{35}$ Magnohard, supra n. 30 at 370

${ }^{36}$ (1994) 20 EHRR 277

37 [2007] UKHL 39, [2008] 1 A.C. 281

${ }^{38}$ As allowed in Page v Smith [1996] 1 AC 155

${ }^{39}$ Merlin (supra n.21) at 572-3.

${ }^{40}$ Magnohard, supra n. 30 at 374

${ }^{41}$ At 379

${ }^{42}$ At 272

${ }^{43}$ Ibid

${ }^{44}$ At 274

${ }^{45}$ Section 26 (2A) Nuclear Installations Act 1965

${ }^{46}$ Article 1(a)(ix) of the amended Convention.

| 47 see-See new section 7(1D) inserted by Article 3 of the Order.

${ }^{48}$ Supra n.7

| ${ }^{49}$ see-See the Birds and Habitats Directives: Directive 2009/147/EC on the conservation of wild birds (codified version); Council Directive 92/43/EEC on the conservation of natural habitats and of wild fauna and flora

${ }_{50}$ Bartoline Ltd $v$ Royal \& Sun Alliance Insurance plc [2007] 1 All ER (Comm) 1043

${ }_{51}^{51}$ The Environmental Damage (Prevention and Remediation)(England) Regulations 2009

${ }_{53}^{52}$ As scheduled in Annex V of the Directive

${ }^{53} R$ (on the application of Seiont Gwyrfai and Llyfni Anglers Society) $v$ Natural Resources Wales [2015] EWHC 3578 (Admin)

${ }_{54}^{54}$ Raffinerie Mediterranee (ERG) SpA v Ministero dello Sviluppo economico (Case No C- 378/08)

${ }_{56}^{55}$ Section $11 \mathrm{~A}(6)$

${ }_{57}^{56}$ Section $11 \mathrm{~A}(1)$

${ }^{57}$ Section $11 \mathrm{~A}(4)(\mathrm{a})$

${ }^{58}$ Part2A, Environmental Protection Act 1990 as amended in England by the Radioactive Contaminated Land (Modification of Enactments)(England) Regulations 2006 (SI 2006/1379) as also amended by SI 2007/3245 and SI 2008/520. See also powers contained in the Environmental Permitting (England and Wales) Regulations 2016 (SI 2016/1154).

${ }^{59}$ As was suggested in Regina (Holding \& Barnes plc) - $v$-Secretary of State for Environment [2001] 2 AC 295, 